\title{
Perspectivas actuales de la filosofía y la pedagogía del deporte
}

\author{
ÒSCAR CHIVA BARTOLL* y FRANCISO JAVIER LÓPEZ FRÍAS*** \\ * Universitat de València (España). ** Penn State Universtty, Kinesiology Department, Rock Ethics Institute
}

La filosofía del deporte, al igual que la pedagogía, la historia y otros estudios humanísticos alrededor del fenómeno deportivo, ha permanecido tradicionalmente en un segundo plano en facultades e instituciones educativas, incluso en aquellas cuyo fin es, precisamente, comprender adecuadamente cómo y por qué jugamos del modo que lo hacemos y con qué finalidades (Kretchmar, 2005). En una reciente editorial de la revista Sport, Ethics and Philosophy, Michael McNamee (2015) hace un repaso de la actualidad, exponiendo cómo a pesar de que la disciplina no para de crecer y ganar protagonismo, sobre todo en el ámbito editorial, no acaba de hacerse el hueco pertinente en la academia.

Por otro lado, este planteamiento deja entrever que algo debería mejorar en la filosofía del deporte, ya que ningún filósofo o, sobre todo, experto en ética del deporte, forma parte de los comités de decisión de las instituciones deportivas que tantas veces aparecen en los medios por casos de corrupción. Ni siquiera, y esto es opinión de los autores que aquí escriben, aunque sea como opción estratégica para aparentar una imagen presumiblemente ética (Chiva, 2014; López Frías, 2014).

Si bien parte de la explicación a esta marginación de la filosofía es explicada por McNamee en relación al descrédito de las humanidades en general, otra parte de responsabilidad recaería sobre los propios filósofos del deporte, quienes a su juicio no actúan del modo adecuado para que sus ideas y propuestas críticas tengan un verdadero impacto sobre la comunidad. Sin menoscabar este argumento, los que aquí escribimos no compartimos tan pesimista visión de la disciplina. En primer lugar, porque no nos parece que la meta de la filosofía del deporte, así como su éxito, deban evaluarse en función de su presencia en ciertas instituciones, sino en su capacidad de presentar buenos argumentos, ideas y críticas.

En segundo lugar, porque creemos que la disciplina sí progresa. Por ejemplo, en el ámbito de filosofía del deporte escrita en castellano se han producido significativos avances en muy poco tiempo. La "Asociación Española de Filosofía» (AEFD) y su revista: «Fair Play. Revista de Filosofía, Ética 
y Derecho del Deporte» fueron constituidas en 2013. Ese mismo año surgió también la «Asociación Latina de Filosofía del Deporte» (Alfid). Ligadas a ambas asociaciones, diversas publicaciones y eventos de carácter científico han sido dedicadas a temas relativos a la disciplina, y el futuro augura que, si bien progresivamente, el debate filosófico-crítico sobre el deporte en nuestra lengua logrará poco a poco dar muestras de su valía, no solo en lo práctico y más inmediato, sino en el largo plazo de las ideas y su influencia sobre la conciencia social.

Que la revista RECERCA, en su afán por presentar y motivar la discusión en torno a las cuestiones actuales de la ética como las neurociencias (Sancho y Zafrilla, 2013), la interculturalidad (Pastor, Adelanto y Guiral, 2011), el activismo social (Dekker y Feenstra, 2015), y la educación de la juventud (Querol y Alcañiz, 2015), haya dedicado este número especial a la ética del deporte es un motivo más para alentar el optimismo respecto al futuro de la disciplina.

Este número especial de RECERCA no es solo una muestra del proceso de florecimiento de la filosofía del deporte, sino que su contenido supone, en sí mismo, una crítica a los criterios eminentemente prácticos, o pragmáticos, que deben servir para evaluar el éxito de la filosofía del deporte. Si bien la praxis está de fondo en cualquiera de los artículos del número monográfico, algunos de ellos comienzan en el ámbito más teórico-ontológico de la disciplina, siendo, sobre todo, el texto de Filip Kobiela el mejor ejemplo de los trabajos de este tipo. Este profesor de la Universidad de Cracovia toma muy en serio la advertencia de R. Scott Kretchmar, uno de los padres de la disciplina, de que para hacer buena ética del deporte hace falta una propuesta metafísica de base. Por ello, rescatando el trabajo de Bernard Suits, propone una interesante discusión sobre los límites que existen entre el jugar (play), el juego (game), y el deporte (sport), relación que en filosofía del deporte llamamos «la tríada lúdica», así como entre las metas de estos. Al fin y al cabo, como Suits muestra, el deporte no es más que una creación que resulta de la introducción de obstáculos innecesarios que han de superarse para alcanzar una meta.

Si en algo destaca el volumen que presentamos es también en diversidad de perspectivas. Además del texto de Kobiela, que se centra en un tema de carácter ontológico, el número cuenta con artículos pertenecientes a áreas de la filosofía del deporte tan diversas como la ética, la estética, la antropología, la metafísica, y la pedagogía. Esta última es el área de enfoque del segundo artículo del volumen, coescrito por Luísa Ávila Da Costa y Teresa Lacerda, de la Universidad de Oporto, junto con Michael McNamee, profesor en la Universidad de Swansea. El texto explora las posibilidades y 
el potencial ético de la educación física. Para ello, localiza elementos de las principales teorías éticas (normas, deberes, virtudes, etc.) que pueden encontrarse en la práctica deportiva. Este trabajo de «rastreo» de los elementos éticos en el deporte no se realiza de un modo exclusivamente teórico, sino que se apoya en entrevistas realizadas a personas en permanente contacto con la actividad deportiva.

El tercer artículo es escrito por Jesús Ilundaín Agurruza, profesor en el Linfield College de Oregón y presidente de la Asociación Internacional de Filosofía del Deporte (IAPS) desde 2013 a 2015, quien nos presenta con un trabajo de corte fenomenológico-existencialista en el que trata de analizar la influencia que el cultivo del movimiento y el deporte tienen en la tarea de lograr la buena vida. Ilundaín es doble protagonista de este número porque su reciente libro Holism and the Cultivation of Excellence in Sports and Performance: Skillful Striving, aparece en la sección de reseñas analizado críticamente por Joshua Bott.

A continuación José Luis Pérez Triviño, presidente de la Asociación Española de Filosofía del Deporte (AEFD) y profesor en la Universidad Pompeu Fabra de Barcelona, en colaboración con Eva Cañizares Rivas, abogada especializada en derecho deportivo y gestión deportiva, presentan un texto de ética del deporte, muy crítico con un problema capital en el deporte profesional actual: la financiación de las instituciones deportivas. Los autores analizan este tema a través de los fondos de inversión y su influencia en el fútbol profesional. Para ello, atienden a dos problemas que éstos pueden generar en el deporte: $a$ ) las obvias diferencias en cuestión de justicia y equilibrio competitivo, y $b$ ) la erosión del interés del espectador en una competición adulterada por las inversiones extraordinarias de capital.

Con un carácter también muy aplicado pero, a la vez, ontológico-metafísico, Antonio Sánchez Pato, decano de la Universidad Católica de Murcia (UCAM), y Francisco de la Torre Olid, catedrático en la UCAM, nos presentan un texto de carácter antropológico-práctico en tanto que descubre las implicaciones que nuestras concepciones del cuerpo tienen en el ámbito de la educación. Para ello, toman como punto de partida los valores estéticos que comunicamos con nuestro cuerpo cuando practicamos deporte, y se aventuran a proponer modos en los que estos valores podrían ser útiles para potenciar el respeto por la dignidad humana, entendido como valor supremo de nuestros sistemas educativos.

Para concluir la sección de artículos, el lector puede encontrar el texto de Carlos Ortiz de Landázuri, profesor en la Universidad de Navarra, en el que analiza críticamente los modelos que se utilizan en neurociencia, neu- 
ropolítica y neuroeconomía para comprender la relación entre la mente y el cerebro.

En la sección de reseñas, la interdisciplinaridad es también la marca dominante. A la ya mencionada de Joshua Bott se unen dos interesantes aportaciones. Por una parte, Paulina Morales presenta una reseña de la obra «Neuroeducación en virtudes cordiales. Cómo reconciliar lo que decimos con lo que hacemos» de María José Codina. En ella se pone de relieve el papel de las neurociencias como marco comprensivo para entender la conexión entre el funcionamiento del cerebro y el desarrollo de campos disciplinares y/o profesionales como, en este caso, el de la educación. Por otra parte, Víctor Páramo reseña la obra «Ética del humor» de Juan Carlos Siurana, en la que se aborda la ética del humor como una nueva ética aplicada que pretende comprender el fenómeno del humor a la luz de sus implicaciones éticas

Por último, los editores de esta edición, confiando en el apoyo que este número de RECERCA supondrá para la evolución de la filosofía del deporte, hemos incluido una breve bibliografía anotada dedicada a proporcionar una selección de las obras más importantes, tanto en castellano como en inglés, para guiar a todo aquel que desee adentrarse y/o conocer mejor los terrenos de la filosofía y ética del deporte.

\section{REFERENCIAS}

Chiva, Ò. (2014): Ética y deporte. Gestión Ética de los servicios de deporte en la universidad. Tesis Doctorals en Xarxa (TDX). Disponible en http:// www.tdx.cat/handle/10803/129726.

Dekker, P. y Feenstra, R. A. (2015): «Activism and Civil Society: Broadening Participation and Deepening Democracy», RECERCA. Revista de Pensament i Anàlisi, 17, pp. 7-13.

Kretchmar, R. S. (2005): Practical pbilosopby of sport and physical activity. Champaign, Human Kinetics.

López FríAs, F. J. (2014): «El deportista como figura moral de nuestro tiempo», Revista Internacional de Derecho y Ética del Deporte, 1, pp. 14-28.

Pastor, B. G.; Adelanto, A. G. y Guiral, J. C. (2011): «Interculturalidad e interdisciplinariedad. Experiencias de investigación e intervención», RECERCA. Revista de Pensament i Anàlisi, 11, pp. 7-10.

Querol, V. A. y AlcaÑIz, M. (2015): «Jóvenes y trayectorias a la vida adulta. Desigualdades, retos y nuevas formas en un contexto de crisis», RECERCA. Revista de Pensament i Anàlisi, 16, pp. 7-12. 
SAnCho, J. C. y Zafrilla, P. J. (2013): «Retos actuales de la neuroética», RECERCA. Revista de Pensament i Anàlisi, 13, pp.6-10.

\section{BIBLIOGRAFÍA ANOTADA}

Los clásicos de la disciplina

Fraleigh, W. P. (1984): Right actions in sport: Etbics for contestants. Champaign, IL: Human Kinetics Publishers.

Kretchmar, R. S. (1994): Practical pbilosopby of sport. Champaign, IL: Human Kinetics.

SIMON, R. L. (1991): Fair play: Sports, values, and society. Boulder:Westview Press.

SuITs, B. (1978): The grasshopper: Games, life, and Utopia. Toronto: University of Toronto Press.

WeIss, P. (1969): Sport: a pbilosopbic inquiry. Carbondale, Ill: Southern Illinois University Press.

Recopilaciones de textos clásicos de la filosofía del deporte

Morgan, W. J., Kretchmar, R. S., Fraleigh, W. P., y Meier, K. V. (1988): Philosophic inquiry in sport. Champaign, Ill: Human Kinetics Publishers.

Morgan, W. J., Meier, K. V., y Schneider,A. J. (2001): Ethics in sport. Champaign, IL: Human Kinetics.

Recopilaciones de textos sobre debates más modernos en la disciplina

Mcnamee, M. J. (2010): The ethics of sports: A reader. London: Routledge.

Mcnamee, M. J., y Morgan, W. J. (2015): Routledge Handbook of the Pbilosophy of Sport. Nueva York: Routledge.

Torres, C. R. (2014): Bloomsbury companion to the philosophy of sport. Londres: Bloomsbury.

Dopaje y mejora del rendimiento deportivo

Mcnamee, M. J. (2014): Sport, medicine, ethics. Oxford: Routledge.

Мıн, A. (2005): Genetically modified atbletes: Biomedical ethics, gene doping and sport. New York: Routledge. 
MøLler, V. (2010): The ethics of doping and anti-doping: Redeeming the soul of sport? London: Routledge.

Economía, sociedad, política y deporte

Desensi, J. T., y Rosenberg, D. (1996): Ethics in sport management. Morgantown, WV: Fitness Information Technology.

Morgan, W. J. (1994): Leftist theories of sport: A critique and reconstruction. Urbana: University of Illinois Press.

Morgan, W. J. (2006): Why sports morally matter. Nueva York: Routledge.

Walsh,A. J., y GiUlianotTI, R. (2007): Ethics, money and sport:This sporting mammon. London: Routledge.

\section{Estética del deporte}

EDGAR, A. (2013): Sport and art. An essay in the bermeneutics of sport. Andover: Routledge Ltd.

Mumford, S. (2012): Watching sport: Aestbetics, etbics and emotion. London: Routledge, Taylor \& Francis Group. 